\title{
Developing GM super cassava for improved health and food security: future challenges in Africa
}

Ademola A Adenle ${ }^{1,2^{*}}$, Ogugua C Aworh ${ }^{3}$, Richard Akromah ${ }^{4}$ and Govindan Parayil ${ }^{1}$

\begin{abstract}
Background: There is an urgent need to solve the problem of micronutrient malnutrition that is prevalent among young children and women in Africa. Genetically modified (GM) biofortified cassava has great potential to solve part of this problem, but controversy surrounding GM technology and lack of awareness, limited facilities, biased news and other factors may hinder the adoption of GM cassava in the future.
\end{abstract}

Method: Using semi-structured interviews in Ghana and Nigeria, this paper examines the perspectives of scientists, including the BioCassava Plus (BC+) team, on the potential adoption of GM cassava for improving health and food security in Africa. The article also examines issues around the regulatory system and transfer and acceptance of GM cassava among scientists.

Results and discussion: The result suggests that an overwhelming majority of scientists agree that GM biofortified cassava will benefit the health of millions in Africa, and that GM cassava conferred with disease and pest resistance will increase cassava production as it is currently plagued by cassava mosaic diseases (CMD). However, respondents are wary of long-term effects of GM cassava on the environment and lack of a regulatory framework to facilitate the adoption of GM cassava. Even though scientists expressed little or no concern about health risks of GM cassava, they were concerned that consumers may express such concerns given limited understanding of GM technology.

Conclusion: The article concludes with a summary of priorities for policy development with regard to adopting biofortified food products.

Keywords: GM biofortified cassava, Health, Food security, Policy, Scientists, Africa, BioCassava Plus (BC+)

\section{Introduction}

Cassava (Manihot esculenta Crantz) is a staple food crop grown by poor farmers on marginal lands, particularly in Africa, Asia and Latin America. Around 200 million tons of cassava are currently produced globally, of which $51 \%, 34 \%$ and $15 \%$ are produced by Africa, Asia and Latin America respectively [1]. Cassava is one of the major sources of farm income and is an important food security crop for the people of Africa. It is the third African major staple food crop after maize and rice, and

\footnotetext{
* Correspondence: adenle@ias.unu.edu

'United Nations University-Institute of Advanced Studies (UNU-IAS), $6 \mathrm{~F}$ International Organisations Centre, Pacifico Yokohama, 1-1-1 Minato Mirai, Nishi-ku, Yokohama 220-8502, Japan

${ }^{2}$ National Graduate Institute for Policy Studies (GRIPS), 7-22-1 Roppongi, Minato-ku, Tokyo 106-8677, Japan

Full list of author information is available at the end of the article
}

contributes about $40 \%$ of the food calories consumed in tropical Africa [2]. Despite the fact that cassava is very limited in nutritional value, particularly essential micronutrients such as vitamin $\mathrm{A}$, iron and zinc, it remains an important diet for over 250 million people in Africa. The provision of adequate essential micronutrients is critical to health improvement in Africa, particularly in SubSaharan Africa (SSA). These essential micronutrients play a significant role in metabolic activities and energy storage in the human body, particularly in women during menstruation and pregnancy, and in children during normal growth and development [3].

Despite the understanding of the importance of micronutrients, micronutrient deficiencies remain a huge problem among young children and women in SSA. More than 800 million people suffer from micronutrient 
malnutrition in developing countries with Africa accounting for almost $50 \%$ of the children who are clinically or sub-clinically deficient in vitamin A, particularly under five years of age $[4,5]$. This deficiency causes (preventable) blindness in children and confers an increased risk of infection due to immune system impairment. Iron deficiency, which causes anemia, is also a problem. According to the United Nations [6], the prevalence of anemia in preschool children ranges from $42 \%$ to $53 \%$ in East and West Africa, respectively. Additionally, it is estimated that in West Africa (Benin and Burkina Faso) the prevalence of anemia $(\mathrm{Hb}<110 \mathrm{~g} / \mathrm{l})$ in children under five years old is more than $80 \%$ [7]. Lastly, in 2004, 453,207 deaths were recorded as a result of zinc deficiency (a major cause of child death due to severe diarrhea) worldwide; 260502 (57\%) of these deaths were in Africa, mainly among children between six months and five years of age [8].

Clearly, the prevalence of diseases caused by micronutrient deficiencies is a reflection of inadequate diets or poor diets in this region. One reason for these poor diets is that the majority of people living in this region are extremely poor and can not afford micronutrient-rich foods such as milk, meat, eggs and fish that normally form part of essential balanced diets. This is simply because these foods are too expensive. Therefore, people in this region need a diverse diet including vegetables, fruits, animalsourced foods and fortified staple foods at low-cost. Although there have been efforts to alleviate micronutrient malnutrition in this region, the diseases remain highly prevalent. Past efforts have included: promoting dietary diversification, promoting improved locally available resources, improving nutritional knowledge, providing pharmaceutical products and/or dietary fortified food supplements. For example, West African countries, such as Burkina Faso and Mali have promoted the increased production of Vitamin A rich-foods in school and local communities through the support of international nongovernmental organizations (NGOs) such as Helen Keller International (HKI) in collaboration with national governments [9]. In another example provided by Birner et al., [9], enriched local products, such as infant porridge (mother-and-child clinics), and locally processed preprepared flours, such as Misola (millet, soya and peanut), have been promoted in a National Plan of Action for $\mathrm{Nu}$ trition and National Program for Food Fortification in Burkina Faso and Mali, respectively. As mentioned, despite some efforts by a few national governments, the majority of people in this region still lack access to a diversified diet due to a high level of poverty, inefficient and poor control of locally available resources, and an inability of the African governments to provide adequate support to, or otherwise prioritize alleviating micronutrient deficiencies as part of their public health programs.
We believe that the development of foods with increased nutritional value and/or content of vitamins and minerals, a process termed biofortification, is required to solve part of the problem of micronutrient malnutrition. Biofortification of staple food crops has been advocated by others as one of the possible solutions to combat the scourge of micronutrient malnutrition in developing countries including Africa [10]. According to the Millennium Development Goal One (MDG-1), "the prevalence of underweight children under five years of age is an indicator where malnutrition contributes in turn to poverty and hunger"[11]. The use of biofortification in reducing child mortality is fundamental to achieving MDG-1by 2015.

For example, reduction of the child-mortality rate of under five-year-olds by two thirds and the maternal mortality rate by three-quarters will require additional technology such as biofortification for nutrition improvement, particularly in isolated areas of Africa and South Asia [12]. Biofortification is believed to be a cost effective means of affecting millions of lives on a sustainable basis in developing countries $[10,13]$, particularly in isolated areas of Africa and South Asia. Production of such biofortified food products can be achieved either through conventional crop breeding or genetic modification as described in section 2. HarvestPlus is one of the programs of the Consultative Group for International Agricultural Research (CGIAR) that was established in 2004 and the first recipient of funding for biofortification research by the Bill and Melinda Gates Foundation [14]. Since its establishment, HarvestPlus has been playing a leading role in biofortification projects with a focus on three previously discussed micronutrients that pose a major health problem in Africa: vitamin A, iron, and zinc. This project is targeted towards improving the nutritional content of seven staple food crops that include sweet potato, pearl millet, beans, maize, wheat and cassava. The goal is improving health among young children and women in developing countries. Also, in 2004, as part of Grand Challenges in Global Health Programs, the Bill and Melinda Gates Foundation made a \$7.5 million commitment to the BioCassava Plus $(\mathrm{BC}+)$ project under the leadership of the Donald Danforth Plant Science Center (DDPSC), St. Louis, MO, USA. This project has two key African partners: Nigerian based National Root Crop Research Institute (NRCRI) and Kenya Agricultural Research Institute (KARI) and also includes other consortium partners from different part of the world (Table 1). The overall aim of $\mathrm{BC}+$ is to develop improved cassava of different varieties particularly in terms of biofortifying cassava with iron, zinc, protein and the vitamin A precursor, $\beta$-carotene. Again, the belief is that biofortified cassava has the ability to improve health and quality of life among poor farmers, including women, and young children in Africa. 
Table 1 BioCassava Plus Project consortium partners

\begin{tabular}{|c|c|c|}
\hline Project consortium partners & Roles & Country \\
\hline \multicolumn{3}{|l|}{ Major consortium partners } \\
\hline Donald Danforth Plant Science Center (DDPSC) & $\begin{array}{l}\text { Overall project management and scientific leadership, } \\
\text { product development, communication, biosafety and } \\
\text { regulatory affairs, intellectual property rights (IPRs), } \\
\text { technical affairs and finance }\end{array}$ & USA \\
\hline National Root Crop Research Institute (NRCRI) & Finance, crop breeding, laboratory, field trials and logistics & Nigeria \\
\hline Kenya Agricultural Research Institute (KARI) & Crop breeding, laboratory and field trials & Kenya \\
\hline \multicolumn{3}{|l|}{ Other consortium partners } \\
\hline International Center for Tropical Agriculture (CIAT) & Cassava breeding and genetic transformation, field trials & Colombia \\
\hline International Institute for Tropical Agriculture (IITA) & Cassava breeding, nutrition assessment & Nigeria \\
\hline Ohio State University & Cassava genetic transformation & USA \\
\hline University of Bath & Cassava genetic transformation & UK \\
\hline Eidgenossische Technische Hochschule (ETH) & Cassava genetic transformation & Switzerland \\
\hline Bill and Melinda Gates Foundation & Donor & USA \\
\hline Monsanto & Donor & USA \\
\hline
\end{tabular}

While this article provides background on biofortification for nutrition enhancement through either conventional breeding or genetic modification (GM), the main purpose of this article is to examine the perceptions of scientists regarding the potential adoption of GM technology for increasing the nutritional content of cassava and improving the agronomic traits of cassava production in general. This study relies on semi-structured interviews with some key members of the $\mathrm{BC}+$ project and relevant scientists in biotechnology and agricultural science at research institutes and universities in Ghana and Nigeria. This research was carried out in the context of a wider study of biotechnology which focuses on GM cassava technology as a relatively new technique which touches upon the vital aspects of benefits and risks that are associated with potential adoption of new technologies. This study concludes with a summary of findings and a list of policy considerations for adoption of biofortified products.

\section{Biofortification for nutritional enhancement in Africa: Is it} conventional breeding or genetic modification?

Given the prevalence of micronutrient malnutrition among young children and women, the development of foods with enhanced nutrients is crucial in Africa, particularly SSA. The technology advancement in this era and subsequent adoption of innovative tools has the potential to pave the way for better crop productivity and higher quality food at lower cost in order to solve the micronutrient problem in this region. The science of biotechnology, either through conventional breeding (often in conjunction with marker assisted selection) or genetic modification approaches has great potential to achieve biofortification for nutritional benefits in SSA.
However, this raises important questions as to which biotechnological approach can be used to achieve biofortification in the most efficient, cost-effective and sustainable manner; both methods have unique capabilities and constraints.

Conventional breeding is achieved by identifying parents with traits that complement each other and which have the ability or capacity to compensate the shortcomings of each other through sexual recombination. This requires selection of offspring with desired traits over a long period of time. For example, production of improved crop lines can take as long as 10 years from the first parental crossing to generation and distribution of selected improved crops. The conventional breeding technique can be used in staple food crops such as rice, wheat, beans, maize, banana and cassava to study the genetics of trace minerals ( for example, iron, zinc, provitamin-A carotenoids) inheritance and, in theory, to improve the nutritional value of such trace minerals in staple crops. This technique has been used for many years in crop production and has created several desired varieties. For example, using conventional breeding, Nigeria-based International Institute for Tropical Agriculture (IITA) has developed several cassava varieties and germplasm with improved yield, quality, disease and pest resistance; more than 200 of these varieties have been distributed and released to African farmers [15]. Similarly, Colombia-based International Center for Tropical Agriculture (CIAT) has also distributed advanced cassava breeding materials to many national programs in Asian and African countries through conventional breeding programs [16]. Other than using conventional breeding for cassava, several papers have reported the use of conventional breeding for improving 
other staple crop varieties in increasing micronutrient density [17-22]. For example, using conventional breeding, a rare variation of a gene called $\operatorname{crtRB1}$ (normally occurring in temperate maize) has resulted in higher production of $ß$-carotene (18-fold) [20], and these traits are being introduced into tropical maize strains which are common in Africa. Another example is orangefleshed sweet potato and orange maize which were biofortified using conventional breeding. These biofortified products, with provitamin-A, have proven to be successful as they are well accepted by young children in rural Mozambique [21,22].

In spite of the potential of conventional breeding, irregular flowering, high degrees of heterozygosity, low seedling number, and genetic variability represent significant drawbacks for cassava breeders [13,23]. The ability of cassava roots to produce enough $B$-carotene to meet the daily requirements of adults (that is., $6 \mathrm{mg} / \mathrm{d} ß$ carotene) is due to the presence of genetic variability in germplasm [24]. Unfortunately, the use of conventional breeding will not be an option where genetic variability for a given trait is too low to achieve the target levels $[24,25]$. Thus, even though desirable varieties of cassava can be conventionally bred, to some level, conventional breeding may prove useless due to problems with other germplasm of cassava. As a result, small-scale farmers are unlikely to benefit from conventional breeding as it might not serve the purpose of improving crop production and increasing the opportunity for large scale farming in tropical areas.

Transgenic methods, otherwise known as genetic modification, are performed by inserting only a small additional piece of information (foreign DNA) into locally adopted and farmer preferred cultivars to control a specific trait within the selected cultivar. This process is achieved through the splicing of a well characterized chunk of foreign DNA containing a particular known gene within the chromosome of a host organism using a pair of molecular scissors called 'restriction enzymes'. Restriction enzymes cut DNA strands at specific restriction sites into specific DNA fragments so that they can be inserted and integrated into the host chromosome at the restriction sites. All this can take place within a relatively short period of time when all the resources required to perform the tasks are available. Given the inability of conventional breeding to perform this specific task in cassava, genetic engineering can be used to fill the gaps. It was 15 years ago, precisely in 1996, when the genetic engineering technique was first developed for cassava transformation. This was carried out by a research group at the Eidgenössische Technische Hochschule (ETH), Switzerland, that produced transgenic cassava via regeneration from embryogenic systems [26], and by research groups at the International
Laboratory for Tropical Agricultural Biotechnology (ILTAB) and the University of Bath, the UK, that produced transgenic cassava via friable embryogenic callus (FEC)[27]. Since the first breakthrough, a growing body of literature [28-31] has reported genetic transformation of cassava, particularly for biofortification, with a focus on nutritional enhancement such as elevating the vitamin, protein and mineral content levels. Other genetic transformations of cassava have also focused on important areas such as reducing cyanogenic content, creating disease and pest resistant varieties, delaying post-harvest physiology deterioration in storage roots, increasing starch production, and improving the overall quality of cassava in general terms [31,32]. The application of transgenic methods has led to a wide range of germplasm with more than 20 cultivars from Africa, Asia and the Americas [33], and has demonstrated a new and highly efficient, robust and reproducible cassava transformation protocol [34].

These transgenic methods have also been applied in biofortification of other staple food crops such as potato, maize, bean and rice [30,35]. A similar approach can be applied to genetic improvement in cassava. For example, successful studies with transgenic potatoes suggests that an increase in total protein and most of the essential amino acids can be achieved [35]. Similarly, in rice, transgenic rice has been developed with increased $\beta$ carotene levels. First, rice called 'Golden Rice 1' (GR1) with $1.6 \mu \mathrm{g} / \mathrm{g}$ total carotenoids (mainly $ß$-carotene) was developed, [36] and later boosted to $37 \mu \mathrm{g} / \mathrm{g}$ total carotenoids for 'Golden Rice 2' (GR2) [37]. The benefit of GR2 for poor and malnourished countries including those in Africa, particularly among young children between oneand three-years-old in terms of recommended dietary allowance $(300 \mu \mathrm{g}$ vitamin A) can be as high as $25 \mu \mathrm{g} / \mathrm{g}$ ßcarotene of $72 \mathrm{~g}$ GR2 based on a retinol equivalence ratio for $\beta$-carotene of $12: 1$. Based on the same ratio (12:1), Bouis et al., [30] reported that total provitamin-A intakes would be increased by $25 \%$ for adult women and preschool children, if GR1 were to replace nontransgenic rice. All of these improvements of various traits represent a significant major trend that could be applied to cassava transformation and clearly can benefit the poor in countries with micronutrient malnutrition.

The use of conventional breeding, marker assisted selection and transgenic methods will largely depend on the regulation, production cost, and suitability required to produce a desired result in terms of achieving nutritional quality. These must be balanced against cost effectiveness in poor countries such as those in SSA. According to Hunt [38], the undernourished may enjoy biofortified varieties for a cost of only US \$0.02-0.03 for a single person per year, compared with commercial iron fortification for a cost of $\$ 0.12$, and iron supplement 
exceeding the cost of $\$ 3.00$ per person based on a World Bank report [39]. This analysis suggests that the cost of iron supplementation is 100 times more than the cost of biofortified rice, indicating how biofortification might save considerable money when it becomes available. While the cost of conventional breeding can be moderately low, for example, $\$ 4$ million per variety over a given period of 10 years (equivalent to $0.2 \%$ of global vitamin A supplement) [12], it will cost between five and eight fold more to produce and regulate a GM, or transgenic, crop [40,41]. However, a previous study by Hunt [38] suggests that development of an iron or zinc-dense variety by conventional method will each cost $\$ 10$ million, which sharply contrasts the subsequent study [12]. In addition, another report [30] argues that higher costs of meeting regulatory approval remain unknown, making it difficult to conclude that transgenic methods will be more or less expensive than conventional methods. Bouis et al., [30] suggests that the higher regulatory costs of transgenics may be offset by greater costs and the lengthy period of time required of conventional methods. In the case of the former, future introduction of comprehensive regulatory procedures based on robust scientific findings may minimize the effect of higher costs, thereby making it more affordable.

In summary, conventional breeding including marker assisted selection [42] and genetic engineering have both been described in terms of their important roles toward crop improvement, particularly biofortification. Even though they are different and complementary ways of improving crops, both are still questionable, particularly in terms of limitations and constraints. While conventional breeding is still a better choice in Africa, due to its technical simplicity, low cost (depending on breeding procedures) and lack of government regulation, this technique is limited due to long breeding cycles and the sexual process itself [25], therefore making it less suitable for biofortification. Genetic engineering has great potential in making conventional breeding faster and more efficient as well as complementing its limitations, particularly in targeting a specific gene trait that requires less need for a large population and multiple generations of selection. In the past 15 years, cassava transgenic technology has made significant progress in terms of enhanced nutritional values (for example., GM biofortified cassava), increased disease and pest resistance, improved starch yield and quality [31,32]. However, transgenic technology is hotly debated around the world with several factors (for example., biosafety regulation, low level of awareness, facilities, infrastructures, and so on) hindering the adoption of new technology in developing countries, including those in Africa. Moreover, the dispute between the US and the European Union (EU) over adoption of GM technology, particularly with regards to the precautionary principle as mandated through the Cartagena Protocol on Biosafety (CPB)[43], has become a political tussle which is one of the major obstacles to potential adoption of GM crops in Africa; this tussle has a serious impact on the African continent as to whether to adopt GM technology or not $[44,45]$. The tough EU regulation through a highly precautionary approach represents a significant challenge to the development of GMO policies in many African countries, and also hinders the opportunity of donating new agricultural technologies that may come under humanitarian purposes by multinational firms and other organizations.

\section{Methodology}

Scientists were interviewed as some of the key stakeholders that play an important role in adopting new agricultural technology. Their perceptions around the potential adoption of GM technology were collected in two West African countries, Ghana and Nigeria, in January, 2011 through a qualitative approach. A qualitative approach was chosen for this study because it offers the opportunity to explore a wider range of issues in much greater detail and it also uncovers new areas that are not anticipated at the outset of the research $[46,47]$. Accordingly, the research questions posed in the study are not amenable to a quantitative approach such as is commonly employed in many large-scale investigations (which are necessarily constrained by decisions on which highly structured questions will be used). Amongst GM crops that are likely to be cultivated in both countries is GM cassava given the ongoing field trial in Nigeria. The West African countries were chosen as they are part of the only region in Africa with a large production of cassava and are therefore two important countries in this region which could benefit from adoption of GM technology for improving cassava production. Nigeria has the largest production of cassava in the world with approximately 34 million tonnes of cassava produced in 2002 [48], Ghana is also among the top ten producers of cassava, occupying the third and sixth position in Africa and the world, respectively, in 2002.

Interviews were conducted using a semi-structured interview style. In most cases some directors of relevant institutes were included in the group of interviewees. Individual interviews and focus groups were employed and comprised groups of six to nine scientists. While several relevant questions were asked regarding adoption of other GM crops such as GM cotton, GM sorghum, GM maize, specific questions on GM cassava were asked given the importance of cassava as a food security crop in the West African region. Potential adoption of GM cassava technology was chosen as an example to elicit relevant opinions from respondents. Specific questions included health improvement and food security, regulatory issues, and 
transfer and acceptance of new technology. A key aspect of the interviews was to ensure that experts selected for interview were relevant in the field and associated with institutions that can influence agricultural or national policy; this approach has previously been adopted in the selection of important stakeholders for policy development [49]. Given the nature of the topic and the possible role of scientists in decision-making, we tried as much as possible to keep the questions neutral to reduce any potential bias in response to our question. For example, what are the risk assessments of GM cassava? (see the Additional file 1 for the details). We identified scientists, in both countries, in the field of agriculture and natural sciences, including biotechnology, at research institutes and universities including the ministry of agriculture. These scientists were identified with the help of each country's government. The Nigeria-based NRCRI was selected due to the ongoing GM cassava field trials and the presence of members of the $\mathrm{BC}+$ project at this institute. The selection also included scientists at the two best universities in the field of agricultural science in the two countries. The total number of respondents for this research is 58: 43 scientists at research institutes and 15 scientists at universities as described in Table 2.

Prior to the interviews, permission was sought from the individual country governments. We explained the objectives of our meetings with the key stakeholders, particularly with regards to potential adoption of GM technology in each country. After the approval from the governments, all the institutes and universities that were contacted agreed to speak with our team on the topic, except the University of Ghana and Nigeria-based IITA that did not participate in the interviews after a formal approach due to some undisclosed reasons. The interviews and discussions were conducted in English, tape recorded and notes were simultaneously taken during the discussions. Following the interviews, audio recordings and notes were immediately transcribed and coded for the analysis of the results. All pieces of key information and important quotes from the interviews were put together for this article.

\section{Results and Discussion}

Scientists' perspectives on GM cassava technology

Scientists' views were sought with regards to GM cassava for improving health and food security in Africa. In Ghana and Nigeria, scientists agreed that GM technology can be important in improving the quality of root and tuber crop production (for example, cassava which is widely consumed in SSA and almost every household in West Africa). Emphasis was laid on nutritional benefits, increased yields and disease resistance in cassava through the application of GM technology. Many scientists stressed that GM technology can be more efficient where traditional plant breeding techniques have historically performed poorly and that the new technology can be useful in solving the micronutrient deficiencies that lead to the death of young children due to chronic malnutrition and poorquality diets. The $\mathrm{BC}+$ team placed much emphasis on the potential of GM cassava in solving nutritional problems such as iron, zinc, vitamin A, and protein deficiencies. This group also stated that the $\mathrm{BC}+$ project's focus on these important components of nutrition has led to the production of more than 10 times the levels of provitamin A in GM cassava compared with non-GM cassava. It is expected that GM cassava will make a significant impact in terms of improving the quality of life and health among poor farmers and consumers in Africa. According to a scientist; ' $B C+$ project wants to deliver nutrient dense cassava that has potential to solve malnutrition problems among young children and women' Another scientist from the $\mathrm{BC}+$ team added: 'GM technology offers a much more effective approach to improve other traits that are present in germplasm 60444 apart from $\beta$-carotene because we don't

Table 2 Interviews conducted at various research institutes and universities in Ghana and Nigeria

\begin{tabular}{lll}
\hline Country & Institutions & Number \\
\hline Ghana & & \\
& Biotechnology and Nuclear Agriculture Research Institute (BNARI) & 9 \\
& Kwame Nkrumah University of Science and Technology (KNUST) & 6 \\
& Crop Research Institute (CRI) & 6 \\
& Regional Agricultural Development Unit (RADU) & 8 \\
& Savannah Agriculture Research Institute (SARI) & 3 \\
Nigeria & & 6 \\
& National Root Crops Research Institute (NRCRI) & 9 \\
& University of Ibadan (UI) & 9 \\
& Lagos State Agricultural Development Authority (LSADA) & 58 \\
& National Biotechnology Development Agency (NABDA) \\
& Total (including individual interviews) \\
\hline
\end{tabular}


have answers to those traits in the germplasm even with application of traditional plant breeding in the past'. According to the $\mathrm{BC}+$ scientists, the Phase I biofortified germplasm 60444 which contains $\beta$-carotene (Figure 1) was first tested in Puerto Rico before the confined field trials in Nigeria which were recently completed at NRCRI (the confined field trial took place between 9 and 12 months). This particular GM cassava trait has been harvested. Currently, there is also an ongoing confined field trial of 60444 iron and zinc nutrient enhanced cassava (Figure 1).

An overwhelming majority of scientists mentioned that creating GM cassava varieties that are resistant to diseases (especially, cassava mosaic disease: CMD) and pests so as to increase the yields of cassava production will be very important. According to the $\mathrm{BC}+$ team, the recently completed field trial of $\beta$-carotene nutrient enhanced cassava did not involve cassava that was genetically modified to be disease resistant. However, there is ongoing transformation of cassava for both disease resistant and nutrient enhancement traits that will be part of Phase II trials. The current 60444 may be susceptible to CMD in Nigeria but this is not a major problem in Puerto Rico due to the lack of widespread CMD in that country. In epidemic areas, the impact of CMD, and other diseases, can be devastating with great losses in yield particularly at early stages. For example, as a result of CMD attack, the yields can be as low as 4 ton/ha or less compared with the normal average yield of 8 ton/ha in Africa which is still below the potential yield of cassava elsewhere. Even in some improved cassava varieties the yield can be very low due to an attack of CMD depending on the degree of severity and time period during which the crop is planted. Moreover, some scientists argued that good yields can be obtained from improved cassava varieties despite an attack of CMD, as the improved cultivars are resistant to some strains of CMD. As described by one of the scientists, an increase in yield by controlling disease attack, particularly in a major staple crop such as cassava is paramount to ensuring food security in Africa, and governments must step up action toward rising agricultural challenges and must embrace innovative tools such as GM technology to solve the food problem.

\section{Regulatory issues}

The regulation of GMO products is a key factor for successful adoption of GM technology in Africa. Specific questions asked included risk assessment in terms of health and environmental safety of GM cassava. Despite the fact that GM technology is said to have the potential to improve crop productivity and improve a variety of traits in cassava, concerns were expressed amongst the scientists about the regulatory process and potential
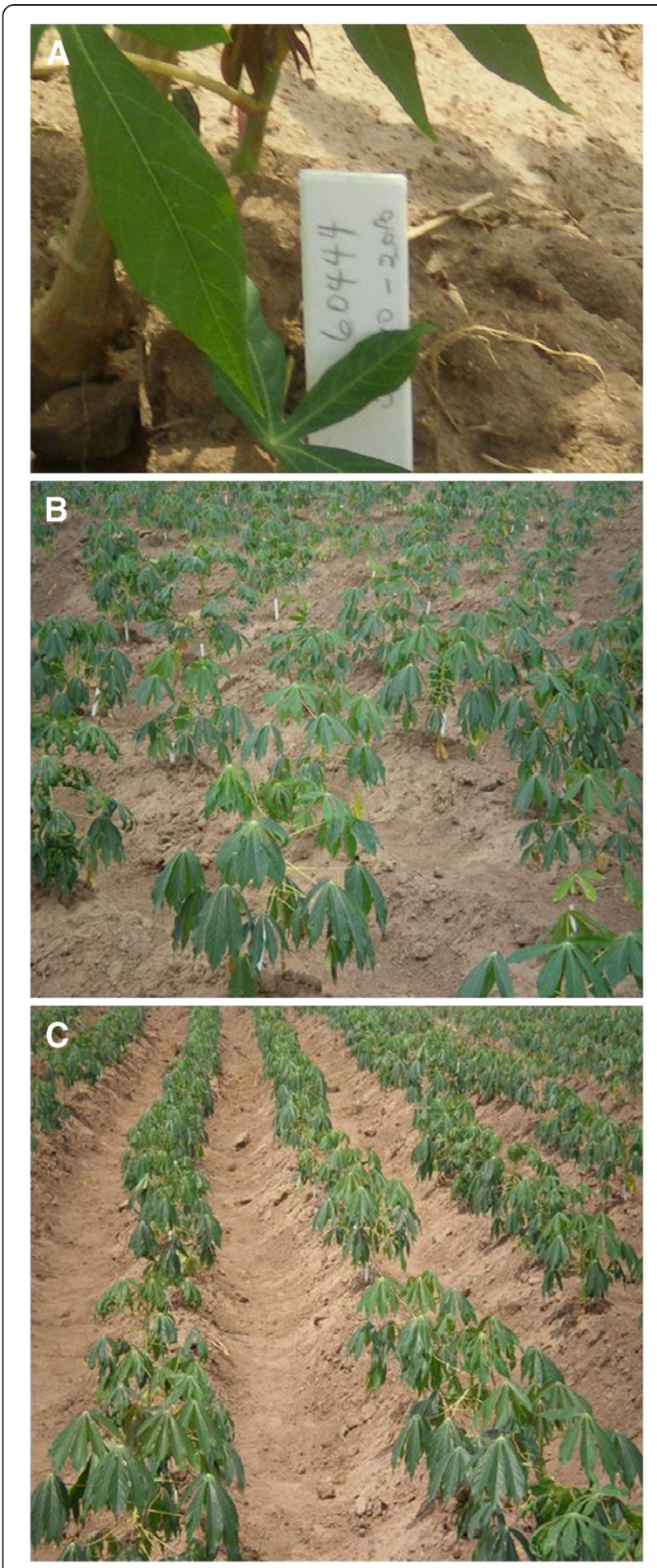

Figure 1 Confined field trials of germplasm 60444 genetically modified (GM) cassava (biofortified). A- Germplasm 60444 GM cassava with provitamin A ( $\beta$-carotene) that has been harvested. B- Germplasm 60444 GM cassava with high iron at early stage. C- Germplasm 60444 GM cassava with high zinc at early stage. 
risks that may be associated with GMO products. Some scientists were wary of the long-term effects of GMO products, particularly with regard to the environmental impact which could spell doom for their indigenous crops. Scientists agreed that the large majority of African governments are not well equipped in terms of regulatory systems for controlling possible adverse effects of GMO products and the need for proper regulation is fundamental to the release of GM cassava. However, there is no evidence yet with regard to a negative impact of GMOs on the environment [50], whereas evidence in terms of benefit to the environment has continued to grow [51]. Currently, only Nigeria and Kenya are conducting confined field trials of GM cassava. However, some Ghanaian scientists mentioned that there may not be a need for confined trials of GM cassava in Ghana due to the ongoing GM cassava trials in Nigeria, but regulatory procedures must be in place to ensure the safety of human health and the environment when it becomes available in Ghana. The regulation of GM cassava could present a significant challenge due to limited facilities and lack of scientific expertise. It is a long-term process to access GM food as such food will have to go through research, testing, safety assessment, screening and market evaluation before being released to farmers and consumers [52].

When asked about the safety evaluation of GM cassava no clear cut strategy or well defined guidelines on the risk assessment process were mentioned for releasing GM cassava in Africa even amongst the $\mathrm{BC}+$ team that participated in the focus group discussion. An attempt to get the majority view from the experts involved in the $\mathrm{BC}+$ project at DDPSC, proved equally difficult. However, an African scientist, and one of the key team members of the $\mathrm{BC}+$ project from the same institute in the US that participated in the interview, said that $\mathrm{BC}+$ has spent considerable time and energy, as a group, to provide answers on the safety evaluation of GM cassava. Biotechnology-derived products are subjected to various analyses on a case-by-case study basis, and a key principle is comparative safety assessment versus a conventional counterpart [53-55]. Thus, GM cassava will have to undergo various standard tests before it can be released in Africa. Whether this will happen in the next five to ten years or less depends largely upon African governments, international regulatory bodies and the $\mathrm{BC}+$ project consortium.

By way of comparison, Golden Rice was developed over ten years ago at a cost of more than \$100 M USD [56] and, despite having gone through some safety assessment tests [53,57], the so called 'Humanitarian Golden Rice' is yet to be released to the beneficiaries in developing countries. This lack of release is attributed to the cumbersome process of regulatory clearance and extreme application of the precautionary principle [58]. Potrykus [58] argues that the rules and regulations established around the world for control and handling of genetically engineered crops can be demanding, as reflected in 10 years spent on preparation of a regulatory dossier for the Golden Rice. In addition to these regulatory hurdles, farmers may be unwilling to adopt Golden Rice and consumers may not accept Golden Rice given the fact that they are used to white rice as opposed to a rice with yellow or golden color. However, a recent study suggests that existing preference for white maize did not affect the acceptance of orange maize (biofortified food product) in Mozambique [22]. Recent opposition to Golden Rice by a scientist who claims that there is no 'Gold' in 'Golden Rice' may also threaten the release of Golden Rice [59]. Currently, golden rice is scheduled to be officially released to farmers in Asian countries by the year 2012 [58], provided all the necessary procedures for release go well.

GM cassava may not escape a tough, high cost, regulatory process similar to the process to which Golden Rice has been subjected. According to the ETH, the review of an application for field testing CMD-resistant cassava in Nigeria would have far exceeded the actual cost of the field test itself (Personal Communication). GM cassava is only at the initial stages of confined field trials in only two African countries. More confined field trials may have to take place in other African countries under stringent and tight regulatory control systems and compulsory tests in line with international safety assessments that may be required before GM cassava is deemed fit for release. A recent report suggests the same [60], specifically noting that more extensive field tests and resistance stability evaluations of GM cassava are required before improved lines can be released for cultivation. It was pointed out among scientists that Africa is a different terrain where there is a history of things often not working out easily, particularly when new tools or techniques are introduced. Whether adequate attention is being paid to developing, maintaining and adapting local capacity to regulate GMOs is deemed very unclear. This view appears to be supported by a recent article [61] which shows that it can be cumbersome to set up and run a well-functioning laboratory for plant biotechnology in Africa. Of course, in order to ensure an effective regulatory process of confined field trials, testing procedures and smooth delivery of GM cassava, there must be functioning laboratories, regulatory authority, enabling agricultural policy and scientific expertise which many African countries lack. Moreover, controversy over potential adoption of GM cassava coupled with NGOs' campaigns against GMOs might present a significant setback for the release of GM cassava in the future (Table 3). While a food crop such as cassava is not 
usually consumed in Europe, it is not clear whether the presence of GM cassava in this region will affect trade relationships with the EU countries given the strict EU precautionary principle on GMOs. Realistically, these are the hurdles that GM cassava may have to face and overcome before it becomes available to the farmers and consumers in Africa.

\section{Can GM cassava technology be effectively transferred to African farmers?}

Technology assessment, transfer processes and the right of farmers to have free access to the technology will be fundamental to successful adoption of GM cassava technology in Africa. When participants were asked to give their opinions or evaluate methods that are put in place to ensure that GM cassava technology reaches farmers in a sustainable manner, not many of them were able to shed light on a successful technology delivery program and/or the future impact of intellectual property rights (IPRs) on GM cassava. However, some participants from the $\mathrm{BC}+$ project described the first attempt taken by local scientists to solve the problem of pests and diseases of germplasm 60444 through breeding. Unfortunately, this attempt was abandoned by Nigerian farmers due to germplasm 60444's susceptibility to diseases and pests as the traditional plant breeding approach failed to solve this problem. They also explained that germplasm 60444 has been sent to laboratories in the US and around the world, and that scientists in these labs have been working on improving the root nutritional and quality traits.

Table 3 Controversies over potential adoption of GM cassava in Africa

\begin{tabular}{|c|c|c|}
\hline \multicolumn{2}{|c|}{ Controversial statements about GM cassava } & \multirow{2}{*}{$\begin{array}{l}\text { References } \\
{[62]}\end{array}$} \\
\hline 1. & $\begin{array}{l}\text { 'A team led by Richard Sayre, a professor of plant cellular and molecular } \\
\text { biology at Ohio State University, had inserted into the cassava's DNA a } \\
\text { bacterial gene that affects starch production. The modified plants' roots were } \\
\text { said to be more numerous and up to } 2.6 \text { times larger than in normal plants.' }\end{array}$ & \\
\hline 2. & $\begin{array}{l}\text { Nagib Nassar, the Brazilian Professor of genetics at the University of Brasilia, } \\
\text { responded to 'GM cassava has 'super size' roots' that 'My colleagues and I } \\
\text { have produced cassava with roots that are ten times the normal size without } \\
\text { resorting to genetic modification.' }\end{array}$ & [63] \\
\hline 3. & $\begin{array}{l}\text { According to DDPSC 'virus-resistance technology will initially be deployed } \\
\text { in the East African region's most popular cassava cultivar (Ebwanatareka) for } \\
\text { adoption by the } 22,000 \text { Kenyan farming families and the project will help } \\
200,000 \text { Kenyan cassava farmers and their families and increase cassava } \\
\text { harvests by } 50 \% \text { on a sustainable basis.' }\end{array}$ & [64] \\
\hline 4. & $\begin{array}{l}\text { Less than } 9 \text { months later a statement by the DDPSC dated May 26, 2006, says } \\
\text { that although resistance to cassava mosaic disease (CMD) had been } \\
\text { established through genetic engineering seven years ago, 'the resistance was } \\
\text { subsequently lost, and changes to the plant's DNA had taken place.' }\end{array}$ & [65] \\
\hline 5. & $\begin{array}{l}\text { 'Many groups oppose the introduction of these seemingly miraculous types of } \\
\text { GM cassava. When asked about the health consequences of consuming GM } \\
\text { foods, Gareth Jones of Biosafety Africa explained simply, 'Nobody really } \\
\text { knows! This is the problem... No long term studies have been done.' }\end{array}$ & {$[66]$} \\
\hline 6. & $\begin{array}{l}\text { The deliberate release of GM into the environment... can lead to irreversible } \\
\text { damage to ecosystems,' explained Glen Tyler of Greenpeace International's } \\
\text { agricultural campaign. 'Once one of these crops is out of the bag, it's hard to } \\
\text { put it back in the bag, so to speak.' }\end{array}$ & [66] \\
\hline 7. & $\begin{array}{l}\text { 'A GM crop research project funded by the Bill and Melinda Gates } \\
\text { Foundation has developed a highly nutritious strain of cassava sufficient to } \\
\text { provide most of a day's nutrients in a single meal'. }\end{array}$ & {$[67]$} \\
\hline 8. & $\begin{array}{l}\text { The world does not need GM cassava and research laboratories should not } \\
\text { turn Africans into guinea pigs on the pretext of helping to fight malnutrition. } \\
\text { GMOs are not the solution to the hunger and nutrition question in Africa.' }\end{array}$ & {$[68]$} \\
\hline 9. & $\begin{array}{l}\text { 'Opponents stood in the way of field trials in Nigeria, Uganda and Kenya by } \\
\text { spreading unfounded scare stories about 'killer cassava'.' }\end{array}$ & [69] \\
\hline 10. & $\begin{array}{l}\text { According to Dr Claude Fauquet of DDPSC 'acquisition of the cassava } \\
\text { genome sequence will provide a platform to explore the vast biodiversity } \\
\text { within cassava wild species. Ultimately, these activities will position cassava } \\
\text { as a valuable source of renewable bio-energy.' }\end{array}$ & [70] \\
\hline 11. & $\begin{array}{l}\text { Critics say, 'the objectives of the project go beyond food security, and touch } \\
\text { on the search by the United States of a cheap source of starch other than } \\
\text { maize to manufacture ethanol to help wean it from oil.' }\end{array}$ & [70] \\
\hline
\end{tabular}


Further, scientists have been sent to the US and the ETH where they have received training on tissue culture and transformation of cassava, particularly on germplasm 60444 which is the focus of the $\mathrm{BC}+$ project's current research. In addition, the respondents said that germplasm 60444 was chosen for the initial tests of GM cassava because it was more amenable to transformation than other available varieties, and on that basis it was accepted for proof of concept. They argued further that this particular cultivar was local to farmers because it has been grown on their farms before, and as a result, the improved new variety through GM technology would be well disseminated and incorporated into their farming systems. These scientists believe that this approach forms part of the technology assessment and transfer process, particularly in modifying and adapting the selected variety or new trait(s) to suit farmers' conditions and environments, thus having a significant impact on the adoption of the new technology when it becomes available.

On the other hand, some scientists argued that technology assessment and transfer processes should go beyond taking a particular variety of cassava for transformation or modification from the farmers, transforming it and then returning it to the farmers. Rather, assessment and transfer must include different types of farm plot trials (for example., initial trials and confirmation trials), extension services, adaptation strategy and other relevant steps that are clearly spelt out as part of a delivery system before the new technology is released to the farmers, and that no technology should be imposed on farmers without following the due process. They are not aware of any established program by the governments or what the future plan is, particularly with regards to reaching out to the farmers while developing biofortified cassava. According to a scientist; 'this is Africa, we don't go through due process because governments, the major player, always thinks it is their right to choose technology for the farmers and impose it on them without assessing the advantages and disadvantages, but the same thing will not happen where the technology is coming from... what we are asking for is type of measures being put in place to introduce GM cassava to our farmers and whether we have it is not clear to us'.

This group of scientists said further that farmers, as one of the key stakeholders, should be involved from the beginning of the technology development process right through until the last stage. They felt this should be accomplished through participatory approach methods such as seminars, training courses and open debates. Further, for the long term prospects of adopting this new technology successfully, obtaining all the necessary information on technology development, particularly in achieving an understanding of end user perception regarding the potential values and benefits of the technology, coupled with the adequate provision of extension services is vital. While little or no information was provided on the delivery program of GM cassava technology during the interviews, introduction of new agricultural technology should be based on a consultative process with the key stakeholders such as the farmers, in order to identify challenges to successful uptake of new technology [71]. For example, identifying the right germplasm based on consultation with the farmers with regard to suitability of the selected variety and ability to grow in any given region or location will save time and facilitate the speedy adoption of newly transformed traits.

The fact that the selected germplasm 60444 only contains nutrient enhanced performance ( $\beta$-carotene) without resistance to diseases may suggest that inadequate consultation with the farmers has taken place and/or failure of the participating scientists to reach a consensus on the importance of introducing the two traits at the same time. As it should be possible to confer both traits of nutrient enhancement and disease resistance to germplasm 60444 at the same time, some felt that this should have been considered during the selection processes. It was clear during the interviews that GM cassava where those two traits are present together has not been created, yet transformation in the laboratory is still ongoing as explained by one of the scientists. Surprisingly, a recent report by Sayre [72], states that biofortification of cassava with elevated provitamin A and cassava mosaic disease virus resistance has been developed through a conventional breeding method. Perhaps this approach should have formed the basis for the transformation of GM cassava from the onset. Moreover, the ETH have also developed CMD-resistant 60444 [34,73] but these transformants have yet to be incorporated into the $\mathrm{BC}+$ project. The ETH CMD-resistant 60444 has been tested for agronomic performance in Puerto Rico for two years but has yet to undergo field trials in Africa due to lack of funding [74]. A similar issue was raised among scientists during a recent interview in Egypt in which it was indicated that they had not been included in the Water Efficient Maize for Africa (WEMA) breeding project on drought tolerant maize [75]. The sidelining of an important product that could have important uses in Africa would appear to reflect a lack of good teamwork among the scientists and funding agencies and/or an incomplete understanding of African farmer's needs. In this case, it would appear that lack of teamwork and lack of proper consultation and/or inability of the scientists to arrive at proper conclusions on a suitable trait may have resulted in wasted resources and time, particularly as field trials and various stages of regulatory assessment are not yet complete. Therefore, it is important to take necessary measures through a 
specific approach and integrated action that will facilitate the development, adoption and diffusion of new technology among the farmers.

The transfer of GM cassava technology to African countries may be seriously constrained in the future as the large majority of scientists interviewed are not aware of government structures or systems in place to ensure that farmers have free access to this new technology, although the $\mathrm{BC}+$ project members claimed that GM cassava technology would be provided to African farmers on a humanitarian basis. But the critical question remains whether Monsanto, which has invested in the $\mathrm{BC}+$ project (over $\$ 6$ million for CMD-resistant cassava), and which holds the patent on the Agrobacterium co-transformation method (the technique used to create transgenic cassava) [76], will keep it free for a short or long period of time. A recent report by Sayre [72] suggests that "these improved varieties will be distributed to farmers for humanitarian purposes either free or at a small cost." The notion of a small cost may suggest that there be might be a twist along the line. It appears for now, provitamin A and other improved nutrient varieties will become available for humanitarian reasons. But what happens when improved agronomic traits (for example., increased yields and starch production) of cassava become available through this transgenic method? Will this become available for humanitarian reasons again in Africa, and what about other developing countries in Asia and Latin America where cassava is used as animal feed and a raw material for starch production and commercial biofuel production (bioethanol)? These IPR issues appear to represent a significant challenge in introducing this new technology into African farming systems, and therefore, should not be considered as a trivial problem despite the so called 'humanitarian way of providing GM cassava technology'. Similar to this point, the technology used to develop drought tolerant maize coordinated under WEMA project is owned by Monsanto [77]. The statement that the drought tolerant maize will be available at a cost within reasonable means of the poor farmers in SSA still lacks clarity and enough information as to how African governments and their farmers benefit from the introduction of these new agricultural technologies despite project collaboration agreement provided on IPRs issues [78]. Given these two examples, some cost may be introduced when this new technology becomes available in the future despite promotion of a humanitarian agenda. African governments should consider that the reality may be that they cannot always get new technology for free and must start negotiating what will benefit their farmers on a long-term basis. Such consideration that includes establishing a proper legal system for IPR so as to facilitate future introduction of new agricultural technologies must be at the heart of national government while working with the African Agriculture Technology Foundation (AATF).

\section{Consumers' acceptance of GM cassava}

Respondents also shared their views on the acceptance of GM cassava by the consumer and its adoption by the farmers. Most respondents agreed that, a modified product based upon cooking, palatability, storage quality and improved nutritional values, particularly protein quality, will promote and increase the acceptance of GM cassava among consumers. Increased yield, disease-resistance and profitability were identified as more likely to remain key issues with respect to farmer adoption of GM cassava. Respondents also indicated that the acceptance of GM cassava would depend on how much information is made available to the public. Issues related to ethics and health safety were suggested as perhaps representing the largest concerns which could be a potential barrier to the acceptance of GM cassava. The media can play an important role in disseminating information on health and safety issues as, in the past, the media have played a significant role in encouraging most people to avoid socalled "contaminated" food products due to health concerns. Regardless, once attention is brought to health risk concerns by the media people will start avoiding it. Additionally, media reports on GM can be negative as they tend to rely on unsubstantiated information without proper investigation [79]. In particular, the information provided tends to come from various sources that are pushing an agenda that this is mostly reported without balanced views.

As described by the scientists (albeit, not necessarily representing the views of consumers), the enhanced nutritional attribute(s) of GM cassava is fundamental to its acceptance by consumers. This view is consistent with similar findings $[80,81]$ that show consumers are more likely to accept biofortified foods including GM cassava due to its improved nutritional values. Wolson [81], however, reports that consumer acceptance will be difficult to win if biofortified products with altered taste, color and texture are introduced to the public. The view of the respondents underlines the fact that, given the health concerns that arose from improved crop varieties in the past, the acceptance of GM cassava will require public education and awareness, particularly with regard to potential benefits and risks associated with GM crops. While emphasis was laid on an effective marketing campaign to inform the public on the benefits of biofortification (for example., GM crops), [80-83] acknowledged a low level of public education on GM crops while assessing their attitudes towards GM crops and foods. These authors emphasized that the public must be educated and informed about the potential benefits and risks of GM crops. 


\section{Conclusion and policy options}

This paper sheds new light on the potential adoption of GM cassava technology in Africa by asking scientists, as one of the key stakeholders, about their perspectives on the new technology. To our knowledge, this is the first study to report scientists' opinions on GM cassava in Africa. This study will add more knowledge and understanding on the potential adoption of this new technology, particularly towards developing appropriate policy to adopt GM technology that will benefit agricultural development in Africa.

In this article, we have only focused on scientists' perspectives, perhaps one of the limitations of this study. However, these scientists agreed that a key need is to also seek opinions of consumers and farmers as other key stakeholders in the future potential adoption of GM cassava. The views of these scientists are fundamental to the successful adoption of GM technology and their advice on potential adoption of this new technology can be a determinant as to whether farmers will adopt the technology or not. While the opinions of scientists, farmers and consumers matter in adopting biofortified food products, so too, does risk assessment. Given the high cost of GMO regulatory processes including risk assessment, there is a need for a cost-effective approach. A recent article proposes a semi-quantitative risk-benefit analysis methodology as a potential tool that requires limited expertise and facilities and can be useful for GMO risk assessment in developing countries [84]. South Africa is likely to take the lead to demonstrate how this innovative tool can balance risks and benefits of GMOs with a view to facilitating a cost effective risk assessment. Given the potential benefits of this new method, national governments should encourage GMO assessments that will facilitate adoption of this kind of accessible tool for better decision making for the regulators in the light of the controversial precautionary principle

Moreover, it also should be stressed that economic studies are needed to analyze the potential benefits of GM cassava, particularly the biofortified products with iron, zinc and provitamin A as there is little or no information on ex-ante socio-economic impact analyses in Africa. The methods and key assumptions for assessing the impacts and cost-effectiveness of biofortification have previously been set out in detail $[85,86]$ and this methodology has been applied in Asia (for example., India, Bangladesh and the Philippine) for calculation based upon optimistic and pessimistic scenarios required for adoption of biofortified foods. This kind of information will be useful for empirical analysis of biofortification in Africa.

The scientists' perceptions about GM cassava technology suggest that this technology has great potential to increase yields, to create disease and pest resistant cultivars, and to increase the nutritional values of cassava. While much emphasis was placed on the human health benefits of GM cassava, little or no concern was raised about health risks. This was in contrast to scientists' beliefs that, based upon previous experience, consumers might express concern about the health risks of any unfamiliar crop product. It was suggested that media reports on GMO products can be very biased and can result in loss of consumer confidence in the introduction of new improved crop varieties. Hence, the scientists felt that GMO products going through proper safety assessments coupled with increased educational efforts targeting the media and the public (for example., potential benefits and risks associated with GMOs) would increase the chance of adoption or acceptance among consumers and farmers. Some concerns were also raised. Uncertainty about the effects of GMO products on the environment remained a serious concern among some scientists, particular concerns were raised about longterm damage to ecosystems and indigenous crops.

Given the perspective of scientists on the potential benefits and concerns in adopting GM cassava in Africa, there is a need for African governments to ensure that an enabling policy environment is created while working together with international partners. Based upon the

Table 4 Summary of policy priority for present and future development of GM biofortified foods

Summary points
1. Engage local institutions and communities in introduction and
adoption of new technology
2. Educate the public, farmers, government institutions, the media and
private companies to increase understanding of GM technology
through communication
3. Establish biosafety cost effective risk-benefit assessments of GMOs
4. Adapt local capacity to assess and safeguard human health and the
environment upon the release of GMO products
5. Aligned support for national plans on nutrition and health issues
must be clearly spelled out in government policy by the Ministry of
Agriculture and Ministry of Health
6. Identify and support national agricultural research institutes and
industries that focus on nutrition enhancement and improvement
(for example, biofortified food)
7. Build national data resources to monitor the progress and impact of
biofortified products
8. Conduct an ex-ante cost benefit analysis to identify and assess
potential market opportunities for biofortified products in different
regions including rural areas
9. Improve infrastructure, processing and marketing sectors for
biofortified products
between local seed sectors and multinational companies
techese problems.
11.Introduce policies that specifically target and address the underlying
social, economic and political causes of undernutrition as
the on IPR


opinions of scientists during the interviews and the current status of achieving biofortification, particularly through genetic modification, this study highlights areas that require policy priority for present and future development of GM biofortified foods as shown in Table 4.

The importance of biofortification in fighting malnutrition can not be overemphasised, but at the same time, it cannot solve the underlying problems responsible for micronutrient malnutrition or food insecurity in Africa. The international community and African governments must increase their efforts in tackling problems such as conflicts, diseases, poverty, climate change, lack of access to food and safe drinking water that contribute largely to the malnutrition problem. In SSA, the number of people affected by extreme poverty doubled from 164 million in 1981 to 313 million in 2002 [87], which contributed significantly to higher malnutrition rates. For example, major malnutrition is not a result of lack of food, but of the high level of poverty, as the majority of these people are extremely poor, and therefore cannot afford to buy food that contains essential nutrients. Added to this, lack of potable water and unacceptable current practices of hygiene, which are very common in Africa, increase the vulnerability to contagious waterborne diseases as one of the main sources of acute malnutrition. Given the existing limited access to food and potable water due to the above factors, governments need to focus on social policy issues that are targeted at solving these problems coupled with implementing appropriate policy as mentioned in Table 4 before biofortification can be a huge success in Africa.

\section{Additional file}

Additional file 1: The following transcript represents only part of exploratory interviews that focused on GM cassava technology.

\section{Competing interests}

The authors declare that they have no competing interests.

\section{Authors' contributions}

AAA collected the data, designed, coordinated and led the study, developed the concepts and the arguments, and wrote the biggest part of the manuscript. OCA and RA contributed to the data collection and wrote part of the manuscript. GP helped design the study and in incorporating the arguments. All authors have read and approved the final manuscript.

\section{Authors' information}

AAA is a Research Fellow in Science and Technology for Sustainable Societies at the UNU-IAS. OCA is a Professor of Food Science at the UI. RA is a Professor of Agricultural Science at the KNUST. GP is a Professor of Science and Technology and the Vice-Rector of the United Nations University and the Director of the UNU-IAS.

\section{Acknowledgments}

AAA would like to thank the Japan Society for the Promotion of Science for support. All interview participants at the research institutes and the universities in Ghana and Nigeria, the Ministry of Agriculture, Ghana and Lagos State Ministry of Agriculture, Nigeria are gratefully acknowledged for their valuable time and contributions. Grateful thanks to three anonymous reviewers for their comments on the article. Special thanks to Nathaniel Szewczyk, John Beeching, Alex Winter-Nelson and Jane Morris for their constructive comments, discussion and helpful review on earlier versions of the manuscript.

\section{Author details}

${ }^{1}$ United Nations University-Institute of Advanced Studies (UNU-IAS), 6F International Organisations Centre, Pacifico Yokohama, 1-1-1 Minato Mirai, Nishi-ku, Yokohama 220-8502, Japan. ${ }^{2}$ National Graduate Institute for Policy Studies (GRIPS), 7-22-1 Roppongi, Minato-ku, Tokyo 106-8677, Japan.

3.Department of Food Technology, University of Ibadan (UI), Ibadan, Nigeria. ${ }^{4}$ Kwame Nkrumah University of Science and Technology (KNUST), Faculty of Agriculture, Kumasi, Ghana.

Received: 21 May 2012 Accepted: 26 July 2012

Published: 21 August 2012

\section{References}

1. FAO: FAOSTAT. 2010. http//:faostat.fao.org

2. IITA: Cassava in Tropical Africa. a reference manual. International Institute of Tropical Agriculture (IITA). Ibandan, Nigeria: 1990.

3. FAO: Food and Agricultural Organization of the United Nations (FAO), State of Food Insecurity in World 2009. FAO, Rome, 2010; 2010.

4. FAO/WHO: Vitamin and mineral requirements in human nutrition. Report of a joint FAO/WHO expert consultation. Bangkok, Thailand:; 1998. 21-30 September.

5. WHO: Micronutrient deficiencies: Iron deficiency anaemia. Geneva: WHO; 2007. http://www.who.int/nutrition/topics/ida/en/. Accessed 10 November 2011.

6. ACC/SCN: United Nations Administrative Committee on Coordination, SubCommittee on Nutrition (ACC/SCN). Forth report on the World nutrition situation: Nutrition throughtout the life cycle. Geneva: ACC/SCN in collaboration with IFPRI; 2000.

7. UNICEF: United Nations Children's Fund (UNICEF). Vitamin and mineral deficiency. A global progress report. New York:; 2004.

8. Walker CLF, Ezzati M, Black RE: Global and regional child mortality and burden of disease attributable to zinc deficiency. Eur J Clin Nutr 2009, 63:591-597.

9. Birner R, Kone SA, Linacre N, Resnick D: Biofortified Foods and Crops in West Africa: Mali and Burkina Faso. AgBioforum 2007, 10:192-200.

10. Bouis HE: Plant breeding: a new tool for fighting micronutrient malnutrition. J Nutr 2002, 131:604S-615S.

11. UNSCN: United Nations-Standing Committee on Nutrition (UNSCN): Nutrition and the MDGs: accelerating progress towards 2015. 2010. http://www.unscn. org/files/Statements/2010_SCN_MDG_Statement_160910_final.pdf. Accessed 10 May 2012

12. Nestel P, Bouis HE, Meenakshi JV, Pfeiffer W: Biofortification of staple food crops. J Nutr 2006, 136:1064-1067.

13. Beyer P: Golden Rice and 'Golden' crops for human nutrition. New Biotechnology. 2010, 27:478-481.

14. HarvestPlus: Micronutrient malnutrition. 2004. http://www.harvestplus.org/ content/about-harvestplus. Accessed 10 November 2011.

15. Manyong VM, Dixon AGO, Makinde KO, Bokanga M, Whyte J: The contribution of IITA-improved cassava to food security in sub-Saharan Africa: an impact study. IITA, Ibadan, Nigeria: IITA report; 2000.

16. Kawano K: Thirty years of cassava breeding for productivity:biological and social factors for success. Crop Sci 2003, 43:1325-1335.

17. Graham RD, Welch RM: Breeding for staple-food crops with high micronutrient density: Agricultural Strategies for Micronutrients. Washington, D.C: Working Paper No 3; International Food Policy Research Institute; 1996.

18. Graham R, Welch R, Bouis $\mathrm{H}$ : Addressing micronutrient malnutrition through the nutritional quality of staple foods: principles, perspectives, and knowledge gaps. Adv Agron 2001, 70:77-142.

19. Graham RD, Senadhira D, Beebe SE, Iglesias C, Ortiz-Monasterio I: Breeding for micronutrient density in edible portions of staple food crops: conventional approaches. Field Crops Res 1999, 60:57-80.

20. Yan J, Kandianis CB, Harjes CE, Bai L, Kim EH, Yang X, et al: Rare genetic variation at Zea mays crtRB1 increases $\beta$-carotene in maize grain. Nat Genet 2010, 42:322-327.

21. Low JW, Arimond M, Osman N, Cunguara B, Zano F, Tschirley D: A FoodBased Approach Introducing Orange-Fleshed Sweet Potatoes Increased 
Vitamin A Intake and Serum Retinol Concentrations in Young Children in Rural Mozambique. J Nutr 2007, 137:1320-1327.

22. Steven $R$, Winter-Nelson A: Consumer acceptance of provitamin Abiofortified maize in Maputo. Mozambique. Food Policy 2008, 33:341-351.

23. Jennings $\mathrm{DL}$, Iglesias C: Breeding for Crop Improvement. In Cassava: Biology. Edited by Hillocks RJ, Thresh JM, Bellotti AC. CAB International: Production and Utilization; 2002:149-166.

24. Iglesias C, Mayer J, Chavez L, Calle F: Genetic potential and stability of carotene content of cassava roots. Euphytica 1997, 94:367-373.

25. Ceballos H, Iglesias CA, Perez JC, Dixon AG: Cassava breeding: opportunities and challenges. Plant Mol Biol 2004, 56(4):503-516.

26. Li HQ, Sautter C, Potrykus I, Pounti-Kaerlas J: Genetic transformation of cassava (Manihot esculentaCrantz). Nat Biotechnol 1996, 14:736-740.

27. Schöpke C, Taylor N, Carcamo R, Konan NK, Marmey P, Henshaw GG, et al: Regeneration of transgenic cassava plants (Manihot esculentaCrantz) from microbombarded embryogenic suspension cultures. Nat Biotechnol 1996, 14:731-735.

28. Taylor N, Chavarriaga P, Raemakers K, Siritunga D, Zhang P: Development and application of transgenic technologies in cassava. Plant Mol Biol 2004, 56(4):671-688

29. Stupak M, Vanderschuren H, Gruissem W, Zhang P: Biotechnological approaches to cassava protein improvement. Trends Food Sci Technol 2006, 17:634-641.

30. Bouis HE, Chassy M, Ochanda O: Genetically modified food crops and their contribution to human nutrition and food quality. Trends Food Sci Technol 2003, 14:191-209.

31. Liu JQ, Zheng Q, Ma Q, Gadidasu KK, Zhang P: Cassava Genetic Transformation and its Application in Breeding. J Integr Plant Biol 2011, 53(7):552-569.

32. Sayre R, Beeching JR, Cahoon EB, Egesi C, Fauquet CM, Fellman J, et al: The BioCassava Plus Program: Biofortification of Cassava for Sub-Saharan Africa. Annu Rev Plant Biol 2011, 62:251-272

33. Raemakers CJJM, Schreuder M, Pereira I, Munyikwa T, Jacobsen E, Visser RGF: Progress made in FEC transformation of cassava. Euphytica 2001, 120:15-24.

34. Bull SE, Owiti JA, Niklaus M, Beeching JR, Gruissem W, Vanderschuren $\mathrm{H}$ : Agrobacterium-mediated transformation of friable embryogenic calli and regeneration of transgenic cassava. Nat Protoc 2009, 4:1845-1854.

35. Chakraborty S, Chakraborty N, Datta A: Increased nutritive value of transgenic potato by expressing a nonallergenic seed albumin gene from Amaranthus hypochondriacus. Proc Natl Acad Sci USA 2000, 97(7):3724-3729.

36. Ye X, Al-Babili S, Klöti A, Zhang J, Lucca P, Beyer P, et al: Engineering the provitamin A (beta-carotene) biosynthetic pathway into (carotenoid-free) rice endosperm. Science 2000, 287:303-305.

37. Paine JA, Shipton CA, Chaggar S, Howells RM, Kennedy MJ, Vernon G, et al: A new version of Golden Rice with increased pro-vitamin A content. Nat Biotechnol 2005, 23:482-487.

38. Hunt JM: Reversing productivity losses from iron deficiency: the economic case. J Nutr 2002, 132:794-801.

39. WB. The World Bank (WB): Enriching lives: overcoming vitamin and mineral malnutrition in developing countries (Development in Practice Series). Washington DC: 1994.

40. Kalaitzandonakes N, Alston JM, Bradford KJ: Compliance costs for regulatory approval of new biotech crops. Nat Biotechnol 2007, 25:509-511.

41. Manalo AJ, Ramon GP: The cost of product development of Bt corn event MON 810 in the Philippines. AgBioforum 2007, 10:19-32.

42. Fauquet CM, Taylor NJ, Tohme J: The Global Cassava Partnership for the 21st Century (GCP21). Tropical Plant Bio 2012, 5:4-8.

43. CBD. Convention on Biological Diversity (CBD): Cartagena Protocol on Biosafety to the Convention on Biological Diversity: text and annexes. Montreal: Secretariat of the Convention on Biological Diversity. 2000. www.biodiv.org/ doc/legal/cartagena-protocol-en.pdf [Accessed: April 22, 2012].

44. Paarlberg R: GMO foods and crops: Africa's choice. New Biotechnol 2010. doi:10.1016/j.nbt.2010.07.005. 2010

45. Adenle AA: Response to issues on GM agriculture in Africa: Are transgenic crops safe? BMC Research Notes 2011, 4:388. doi:10.1186/17560500-4-388

46. Britten N: Qualitative Research: Qualitative interviews in medical research. BMJ 1995, 311:251.
47. Thomas DR: A general inductive approach for qualitative data analysis. New Zealand: School of Population Health University of Auckland; 2003. http:// www.fmhs.auckland.ac.nz/soph/centres/hrmas/_docs/Inductive2003.pdf. Accessed 10 November 2011.

48. FAO: A cassava industrial revolution in Nigeria.: Cassava production; 2004. http://www.fao.org/docrep/007/y5548e/y5548e07.htm. Accessed 10 November 2011.

49. Laumann EO, Knoke D: The Organisational State. The University of Wisconsin Press, Madison: Social Choice in National Policy Domains; 1987.

50. Sanvido O, Romeis J, Bigler F: Ecological impacts of genetically modified crops: ten years of field research and commercial cultivation. Adv Biochem Eng Biotechnol 2007, 107:235-278.

51. Carpenter JE: Impacts of GM crops on biodiversity. Landes Bioscience. 2011, 2:1-17.

52. Carman J, Is GM: Food Safe to Eat? In Recoding Nature Critical Perspectives on Genetic Engineering. Edited by Hindmarsh R, Lawrence G. Sydney: UNSW Press; 82:93-2004

53. ILSI: Nutritional and safety assessments of foods and feed nutritionally improved through biotechnology. Comput Rev Food Sci Food Safety 2004 3:3-64.

54. Konig A, Cockburn A, Crevel RW, Debruyne E, Graftstroem R, Hammerling U, et al: Assessment of safety of foods derived from genetically modified (GM) crops. Food Chem Toxicol 2004, 42:1047-1088.

55. EFSA: Safety and Nutritional Assessment of GM plants and derived food and feed: The role of animal feeding trials. Report of EFSA GMO Panel Working Group on Animal Feeding Trials. Food Chem Toxicol 2008, 46:S2-S70.

56. Ho M-W: "Golden Rice"- an exercise in how not to do science." Third World Network Biotechnology and Biosafety Series No. 6 (2000): April 1. 2010.

57. Chassy B, Egnin M, Gao Y, Glenn K, Kleter GA, Nestel P, et al: Recent Developments in the Safety and Nutritional Assessment of Nutritionally Improved Foods and Feeds. Comprehensive Reviews in Food Science and Food Safety 2008, 7(1):50-113

58. Potrykus I: Lessons from the 'Humanitarian Golden Rice' project: regulation prevents development of public good genetically engineered crop products. New Biotechnology 2010, 27:466-472.

59. Corpuz GA, Yee-Bee D, Hoffman JL: No gold in golden rice, says GMO expert All Voices. 25 August. 2011. http://www.allvoices.com/contributed-news/ 10146190-no-gold-in-golden-rice-says-gmo-expert. Accessed 10 November, 2011.

60. Vanderschuren H, Stupak M, Fütterer J, Gruissem W, Zhang P: Engineering resistance to geminiviruses - review and perspectives. Plant Biotechnol 2007, 5:207-220

61. Bull SE, Ndunguru J, Gruissem W, Beeching JR, Vanderschuren H: Cassava: constraints to production and transfer of biotechnology to African laboratories. Plant Cell Rep 2011, 30:779-787.

62. Sawahel W: "GM cassava has 'super size' roots", SciDev.net, 15 May.: ; 2006 http://www.scidev.net/en/news/gm-cassava-has-super-size-roots.html> Accessed 11 August 2012.

63. Nassa N: "Boosting cassava roots the non-GM way", SciDev.Net, 31 May. 2006. http://www.scidev.net/en/editor-letters/boosting-cassava-roots-the-nongmway.html> Accessed 11 August 2012.

64. EAM: Doubts Over Cassava Project. East African Magazine (EAM)11 September. 2006. http://www.gene.ch/genet/2006/Sep/msg00030.html. Accessed 11 August 2012.

65. GMWATCH: GM Cassava "Our only hope". 2009. http://www.gmwatch.org/ gm-myths/11156-gm-cassava-qour-only-hopeq. Accessed 10 November 2011.

66. Broach S: Genetically Modified Cassava. The Yale Globalist. May 10. 2011. http://tyglobalist.org/front-page/features/genetically-modified-cassava-newtechnologies-have-complicated-the-challenge-of-feeding-africa/> Accessed 11 August 2012

67. ABC. Agricultural Biotechnology Council (ABC): GMObserver: News about farming and GM in the United Kingdom. 2006. http://www.abcinformation. org/library/files/Issue\%209v3\%20FINAL.pdf. Accessed 10 November 2011.

68. FoEA. Friends of the Earth Africa (FoEA): Genetically Engineered Cassava. A threat to Africa's Food Sovereignty. 2006. http://www.eraction.org/ publications/cassava fact_sheet.pdf. Accessed 10 November 2011.

69. Burns G: A plant of last resort: Biocassava a meal ticket for famine-stricken East Africa. 1 October, Chicago Tribune. 2011. http://articles.chicagotribune. 
com/2011-10-01/news/ct-oped-1002-cassava-20110930_1_cassava-geneticengineering-famine. Accessed 10 November, 2011.

70. Biopact: Controversy over transgenic cassava project: US accused of pushing GM cassava for biofuels from Africa. September 13. 2006. http://news. mongabay.com/bioenergy/2006/09/controversy-over-transgenic-cassava. html. Accessed 10 November 2011.

71. Ashby JA: Evaluating technology with farmers: In A Hand Book of IPRA project. CIAT, Colombia: CIAT and the Kellog foundation; 1990.

72. Sayre RT: Biofortification of cassava for Africa: the BioCassava Plus Program. Chapter 11. London UK: Smith-Gordon; 2011:113-120.

73. Vanderschuren H, Alder A, Zhang P, Gruissem W: Dose-dependent RNAimediated geminivirus resistance in the tropical root crop cassava. Plant Mol Biol 2009, 70:265-272.

74. Gruissem W: email of 14 November 2011 sent to Ademola Adenle from Gruissem Wilhelm. 2011.

75. NU-IAS: Interviews conducted by Dr. Ademola Adenle at the United Nations University-Institute of Advanced Studies (UNU-IAS) on Genetic Modified (GM) Agriculture in Egypt, June. 2012.

76. Pray C, Naseem A: Intellectual Property Rights on Research Tools: Incentives or Barriers to Innovation? Case Studies of Rice Genomics and Plant Transformation Technologies. AgBioforum 2005, 8(2\&3):108-117.

77. WEMA: Water Effecient Maize for Africa (WEMA). Progress Report. March. 2011. http://www.aatf-africa.org/userfiles/WEMA-Progress-Report_2008-2011.pdf. Accessed 11 August 2012.

78. AATF: African Agricultural Technology Foundation (AATF). WEMA Management Response to ESCC Audit report 2010 Key Findings and Recommendations. 2010. http://www.aatf-africa.org/userfiles/WEMA-Management-ResponseESCC-Audit-2010.pdf. Accessed 11 August, 2012.

79. Mashood E: The GM Debate-Who Decides? Analysis of decision-making about genetically modified crops in developing countries. Panos Report No 49.2004. http://panos.org.uk/wp-content/files/2011/03/gm_debate_reportwZacCL. pdf> Accessed 11 August 2012.

80. Gonzalez C, Johnson N, Qaim M: Consumer Acceptance of SecondGeneration GM Foods: The Case of Biofortified Cassava in the North-east of Brazil. J Agric Econ 2009, 60:604-624.

81. Wolson RA: Assessing the Prospects for the Adoption of Biofortified Crops in South Africa. AgBioforum 2007, 10:184-191.

82. Aerni P, Bernauer T: Stakeholder Attitudes Toward GMOs in the Philippines, Mexico, and South Africa:The Issue of Public Trust. World Dev 2006, 34:557-575.

83. Krishna W, Qaim M: Consumer attitudes towards GM food and pesticide residues in India Review of Agricultural Economics. 2008, 30:233-251.

84. Morris EJ: A semi-quantitative approach to GMO risk-benefit analysis. Transgenic Res 2011, 20:1055-1071.

85. Stein AJ, Meenakshi JV, Qaim M, Nestel P, Sachdev HPS, Bhutta ZA: Analyzing the Health Benefits of Biofortified Staple Crops by Means of the Disability-Adjusted Life Years Approach: a Handbook Focusing on Iron, Zinc and Vitamin A. HarvestPlus Technical Monograph 4.: Washington, DC and Cali: International Food Policy Research Institute (IFPRI) and International Center for Tropical Agriculture (CIAT); 2005. http://www.ifpri.org/sites/ default/files/publications/hptech04.pdf>. Accessed 11 August 2012.

86. Meenakshi JV, Johnson N, Manyong VM, De Groote H, Javelosa J, Yanggen D, et al: How cost-effective is biofortification in combating micronutrient malnutrition? An ex-ante assessment. World Dev 2010, 38:64-75.

87. Labonté R, Schrecker T: Globalization and social determinants of health: The role of the global marketplace (part 2 of 3). Glob Heal 2007, 3:6. doi:10.1186/1744-8603-3-6.

doi:10.1186/2048-7010-1-11

Cite this article as: Adenle et al:: Developing GM super cassava for improved health and food security: future challenges in Africa.

Agriculture \& Food Security 2012 1:11.

\section{Submit your next manuscript to BioMed Central and take full advantage of:}

- Convenient online submission

- Thorough peer review

- No space constraints or color figure charges

- Immediate publication on acceptance

- Inclusion in PubMed, CAS, Scopus and Google Scholar

- Research which is freely available for redistribution

Submit your manuscript at www.biomedcentral.com/submit 